\title{
Obezite için laparoskopik sleeve gastrektomi'nin 4 yıllık uzun dönem metabolik, ghrelin seviyesi ve komorbidite değişimi üzerine etkileri ve sonuçları
}

\author{
Effects and results of laparoscopic sleeve gastrectomy for obesity on 4-year long-term \\ metabolic, ghrelin level and comorbidity change
}

Onur Kılıç, Onur Birsen, Asıı Mete

Gönderilme tarihi: 03.08.2019

Kabul tarihi: 02.01.2020

Özet

Amaç: Laparoskopik Sleeve Gastrektemi'nin (LSG) orta ve uzun dönem etkilerini, pre-op ve post-op uzun dönem (4 yıl) ghrelin düzeylerinin karşılaştırılması, hastaların LSG sonrası uzun dönemde tekrar kilo alıp almadıkları, obeziteye eşlik eden komorbiditelerin değişimini araştırmaktır.

Gereç ve yöntem: Pamukkale Üniversitesi Genel Cerrahi Anabilim Dalı'nda morbid obezite tanısı ile cerrahi için seçilen, işlem öncesi ghrelin düzeylerine bakılan toplam 34 hastada, Ocak 2009 ve Aralık 2011 tarihleri arasında obezite tedavisi olarak LSG uygulandı. Hastaların ameliyattan sonra 1. ay, 3. ay, 6. ay, 12. ay ve daha sonrasında yıllık kontrolleri yapıldı. En sonunda, post-op 4. yılda hastalarla iletişim kurulup son kontrol ve tetkikleri için çağrıldı.

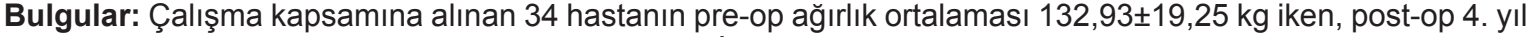
$83 \pm 13,90 \mathrm{~kg}$ oldu. Ameliyat esnasında ortalama BMi: $49,8 \pm 7,3 \mathrm{~kg} / \mathrm{m} 2$ idi. LSG ameliyatı sonrası 4 . yıl sonunda BMi: $29,18 \pm 5,6 \mathrm{~kg} / \mathrm{m} 2$ olarak bulundu. Çalışmaya dahil edilen hastalarda pre-op ghrelin değeri $672 \pm 143 \mathrm{pg} /$ $\mathrm{ml}$ iken, post-op 4.yıl ghrelin değeri $164 \pm 43 \mathrm{pg} / \mathrm{ml}$ oldu. Pre-op ve post-op 4. yıl değerleri arasındaki fark istatistiksel olarak anlamlıydı. Çalışma grubundaki hiçbir hastada, majör komplikasyon ya da takip süresince mortalite izlenmedi.

Sonuç: LSG sonrası ghrelin düzeyi, midenin fundus ve gövdesinin rezeksiyonu nedeniyle azaltılarak karbonhidrat ve yağ tüketimini düşürür. LSG ile obezite tedavisi Tip 2 DM ve HT gibi komorbiditelerin semptomlarını azaltarak hastaların sağlık durumları üzerinde doğrudan yararlı etkiye sahiptir. Elde ettiğimiz verilere göre, LSG morbid obezitenin tedavisinde emniyetli ve etkin bir yöntemdir, uzun dönemli olumlu metabolik etkilere sahiptir, yaşam kalitesi ve konforunu artırıcı bir prosedürdür.

Anahtar kelimeler: Laparoskopik sleeve gastrektomi, morbid obezite, girelin, komorbidite.

Kılıç O, Mete A, Birsen O. Obezite için laparoskopik sleeve gastrektomi'nin 4 yıllık uzun dönem metabolik, ghrelin seviyesi ve komorbidite değişimi üzerine etkileri ve sonuçları. Pam Med J 2020;13:193-198.

\footnotetext{
Abstract

Purpose: The aim of this study is to investigate the moderate and long-term effects of Laparoscopic Sleeve Gastrectomy (LSG), the comparison of pre-op and post-op long-term (4 years) ghrelin levels, whether patients have gained weight again after LSG or not, and the change of the comorbidities accompanying obesity.

Material and methods: LSG was administered as an obesity treatment between January 2009 and December 2011 in a total of 34 patients selected for surgery with the diagnosis of morbid obesity, whose pre-treatment ghrelin levels were measured, at Pamukkale University Department of General Surgery. 1st month, 3rd month, 6th month, 12th month and then annual controls of the patients after the surgery were conducted. Finally, patients were contacted in the post-op 4th year and they were called for their final control and examinations.

Results: The mean pre-op weight of the 34 patients included in the study was $132.93 \pm 19.25 \mathrm{~kg}$, whereas the mean weight in the post-op 4th year was $83 \pm 13.90 \mathrm{~kg}$. During the surgery, mean BMI: was $49.8 \pm 7.3 \mathrm{~kg} / \mathrm{m} 2$. At the end of 4th year after the LSG surgery, BMI: was found as $29.18 \pm 5.6 \mathrm{~kg} / \mathrm{m} 2$. While the pre-op ghrelin value of the patients included in the study was $672 \pm 143 \mathrm{pg} / \mathrm{ml}$, their post-op 4th year ghrelin value became $164 \pm 43 \mathrm{pg} /$ $\mathrm{ml}$. The difference between the pre-op and post-op 4th year was statistically significant. None of the patients in the study group had any major complications or mortality during follow-up.

Conclusions: The ghrelin level after LSG gradually reduces the carbohydrate and fat consumption due to the resection of the fundus and the body of the stomach. Obesity therapy with LSG has a direct beneficial effect on the health status of the patients by reducing the symptoms of the comorbidities such as Type 2 DM and HT.

Onur Kılıç, Op. Dr. Department of General Surgery, Alsancak Nevval Salih İş Gören City Hospital, IZMiR, e-mail: onurkilic3506@hotmail. com(orcid.org/0000-0002-6833-6462) (Responsible Author)

Onur Birsen, Assoc. Prof. Department of General Surgery, Pamukkale University Hospital and Faculty of Medicine, DENiZLI, e-mail: birsenonur@ yahoo.com (orcid.org/0000-0001-6064-5693)

Aslı Mete, Assis. Prof. Department of Anesthesia and Reanimation, Pamukkale University Hospital and Faculty of Medicine, DENIZLI, e-mail: aslimete22@hotmail.com(orcid.org/0000-0002-5621-7407)
} 
According to the findings, LSG is a safe and effective method in the treatment of morbid obesity, has long-term positive metabolic effects, and is a procedure that increases the quality of life and comfort.

Key words: Laparoscopic sleeve gastrectomy, morbid obesity, ghrelin, comorbidity.

Kılıç O, Mete A, Birsen O. Effects and results of laparoscopic sleeve gastrectomy for obesity on 4-year long-term metabolic, ghrelin level and comorbidity change. Pam Tıp Derg 2020;13:193-198.

\section{Giriş}

Obezite, dünya çapında bir salgın hastalıktır ve $A B D$ `de yetişkin nüfusun $\% 36$ 'sını, pediatrik popülasyonun $\% 17$ 'sini etkiler [1]. Obezite aşırı miktarda vücut yağı olarak tanımlanabilir [2]. Obezitenin klinik yönetimi karmaşık ve sıklıkla başarısızdır. Fazla kilolu veya obez olmak, tip 2 diyabet, kardiyovasküler hastalık, uyku apnesi, kronik ağrı ve bazı kanserler dahil birçok komorbidite için bir risk faktörüdür [3]. Morbid obezite için cerrahi tedavi, laparoskopinin ortaya çıkmasından bu yana önemli bir gelişime tanık oldu. Morbid obeziteyi tedavi etmek için bol miktarda varyasyona sahip birçok operasyon halihazırda seçilecek yöntem olarak savunulmaktadır. Laparoskopik sleeve gastrektomi (LSG), başlangıçta kesin bariatrik müdahaleyi bekleyen süper obez hastalar için köprüleme prosedürü olarak tasarlanmıştır. Illerleyen zamanlarda, umut vaat eden erken sonuçlardan sonra, sleeve gastrektomi, morbid obezite için potansiyel tekli ve nihai tedavi olarak farklı yazarlar tarafından önerildi [4-6].

Gastrointestinal peptit hormonu girelin, 1999 yılında büyüme hormonu sekretagog reseptörünün endojen ligandı olarak keşfedilmiştir [7]. Girelin, büyüme hormonu salınımı, iştahın uyarılması ve yağ birikimi gibi çeşitli fizyolojik fonksiyonlara sahiptir. Girelin tokluk sinyalini ileten tek periferik hormondur [8]. Artan kanıtlar, sistemik enerji metabolizmasının düzenlenmesinin ötesine geçen hormon için daha karmaşık ve nüanslı rolleri desteklemektedir. Son yıllarda girelinin, öğrenme ve hafıza, bağırsak motilitesi ve mide asidi salgısı, uyku/uyanma ritmi, ödül arama davranışı, tat hissi ve glikoz metabolizması gibi farklı alanlarda bol miktarda merkezi ve periferik etkileri olduğu bulunmuştur [7].

Aşırı kilolu veya obez hastalarda kilo kaybı, prediyabetli veya glikoz toleransı bozulmuş bireylerde diyabetin başlamasını geciktirebilir veya önleyebilir ve Tip2 DM'li hastalarda kan şekeri kontrolünü önemli ölçüde artırabilir [9, 10].

Laparoskopik sleeve gastrektomi, kilo kayıp oranından bağımsız olarak postoperatif ilk günden itibaren kan glukoz homeostazı üzerine olumlu etki göstermektedir [11]. Tip 2 Diayabetes Mellitus (T2DM) hastalarında yapılan çalışmalar LSG'nin insülin sekresyonunun ilk fazını ve insülin sensitivitesini postoperatif erken dönemde iyileştirdiğini göstermektedir [12].

Çalışmamızda amacımız, kliniğimizde sıkça yapılan LSG'nin orta ve uzun dönem etkilerini, pre-op ve post-op uzun dönem (en az 3 yıl) girelin düzeylerinin karşılaştırılması, hastaların LSG sonrası uzun dönemde tekrar kilo alıp almadıkları, obeziteye eşlik eden komorbiditelerin değişimini araştırmaktır.

\section{Metod}

\section{Çalışma dizaynı ve hasta seçimi}

Pamukkale Üniversitesi Genel Cerrahi Anabilim Dalı'nda morbid obezite tanısı ile cerrahi için seçilen, işlem öncesi girelin düzeylerine bakılan toplam 34 hastada, Ocak 2009 ve Aralık 2011 arasında dönemde obezite tedavisi olarak LSG uygulandı. Bariatrik cerrahi için dahil etme kriterleri olarak $1991 \mathrm{NIH}$ kılavuzları kullanıldı. Tüm hastalar multidisipliner bir yaklaşımla değerlendirildi. Çalışmamızda ameliyatsız zayıflayan hastaların genel cerrahi polikliniğine başvurusu bulunmadığı için incelenmesi yapılamadı. Kliniğimizde kilo kaybı operasyonu olarak tecrübelerimize dayanarak LSG uygun yöntem olarak belirlenmiştir. Sonuçta çalışma kapsamına alınan tüm hastalar LSG'den beklenen faydayı gördü.

Hastaların ameliyattan sonra 1. ay, 3. ay, 6. ay, 1. yıl ve daha sonrasında yıllık kontrolleri toplam 4 yıl boyunca yapıldı. Şikayetleri olduğunda ise hemen kontrole çağrıldı. 


\section{Gereç ve yöntem}

Hastalara işlem öncesi obezite nedeni olabilecek ve obeziteye eşlik edebilecek hastalıklara yönelik sorgulama yapıldı. Operasyon öncesi tüm hastalardan medikal tedavi yöntemleri, diyet, egzersiz ve yaşam tarzı değişiklikleri ile zayıflamak için en az altı ay süre ile profesyonel yardım almaları istendi. $\mathrm{Bu}$ yöntemler ile kilo veremeyenler $\mathrm{NIH}^{\prime}$ in belirlediği endikasyonlara göre LSG bariatrik cerrahi yöntemi, tüm risk ve komplikasyonları anlatılarak önerildi. İlaç ya da alkol bağımlılığı, psikotik bozukluğu olan hastalara cerrahi tedavi önerilmedi.

Hastaların operasyon öncesi boy/kilo değerleri kaydedildi. Çalışmamızda bulunan 34 hastanın pre-op BMi: 49,8 $\pm 7,3 \mathrm{~kg} / \mathrm{m}^{2}$ (35-67 $\mathrm{kg} / \mathrm{m}^{2}$ aralığında) bulundu. Çalışma popülasyonunun demografik verileri Tablo 1 'de verilmiştir. Cerrahi öncesi hastalara rutin biyokimyasal tetkikler, hemogram, tiroid fonksiyon testleri yapıldı. PA AC grafisi çekildi, hastalar endokrinoloji ve metabolizma uzmanı ile değerlendirildi. Deksametazon yükleme testi yapıldı. Daha sonra Kardiyolojik değerlendirme ile EKG ve ekokardiyografi, Göğüs Hastalıkları konsültasyonu, solunum fonksiyon testleri, arteriyel kan gazları tetkiki, gerekli görüldüğünde ise polisomnografi yapıldı. Rutin olarak özefagogastroskopik inceleme yapıldı. Ameliyat öncesi gece saat 24:00'de enoxaparine sc uygulandı.

Tablo 1. Hastaların demografik verileri.

\begin{tabular}{|c|c|}
\hline $\mathrm{n}$ & 34 \\
\hline Cinsiyet (k/e) & $23 / 11$ \\
\hline Yaş, orttss, (yıl) & $35,9+9,54$ \\
\hline BMI, ort $\pm s s,\left(k g / m^{2}\right)$ & $49,8 \pm 7,3$ \\
\hline Ağırlık, ortıss, (kg) & $132,93 \pm 19,25$ \\
\hline \multicolumn{2}{|c|}{ Preoperatif komorbidite } \\
\hline HT, n (\%) & $8(23,6)$ \\
\hline Tip 2 DM, n (\%) & $9(26,4)$ \\
\hline
\end{tabular}

\section{Cerrahi teknik}

LSG standart bir şekilde gerçekleştirildi. Darlık oluşmaması için 32-Fr buji kullanılarak üç adet kalın doku (Echelon, Ethicon Endosurgery ya da EndoGíA, Covidien yeşil $60 \mathrm{~mm}, 2,5$ $\mathrm{mm}, A B D$ ), üç ya da dört adet orta kalın doku (Echelon, Ethicon Endosurgery gold $60 \mathrm{~mm}, 1,8$ $\mathrm{mm}, \mathrm{ABD}$ ) stapler kartuşu yardımı ile antrumdan mide his açısına kadar vertikal hatta transekte edildi.

Stapler hattını güçlendirici olarak peristrip dry, seamguard ya da duet kartuş kullanıldı. Stapler hattında kanayan noktalara orta boy hemoklip uygulandı. Postoperatif 1. gün anastomoz kaçağı ve darlık değerlendirmesi için floroskopi altında, iyonik oral kontrast madde olan diatrizoate ile özefagogastrik inceleme yapıldı. Hastalar ameliyat sonrası ilk haftada berrak sıvı gıdaları, ikinci haftada sıvı gıdaları, üçüncü haftada püre haline getirilmiş gıdaları, dördüncü haftada katı gıdaları tüketti.

\section{Girelin testi}

Tüm hastaların plazma girelin değerleri elisa yöntemi ile ölçülüp, not edildi. Buna göre çalışma kapsamına alınan hastaların pre-op girelin değeri ortalama $672 \pm 143 \mathrm{pg} / \mathrm{ml}$ bulundu.

\section{İstatistiksel analiz}

Sürekli değişkenler ortalama \pm standart sapma, kategorik değişkenler sayı ve yüzde olarak verildi. Bağımsız grup farklılıkların karşılaştırılmasında İki Ortalama Arasındaki Farkın Önemlilik Testi kullanıldı. Bağımlı grup karşılaştırmalarında, Tekrarlı Ölçümlerde Varyans Analizi ve Mcnemar Testi kullanıldı. $p<0,05$ istatistiksel olarak anlamlı kabul edildi.

Sonuç olarak, Ocak 2009-Aralık 2011 tarihleri arasında, seçilen 34 hastaya morbid obezite tanısıyla LSG yapılmıştı. Çalışma kapsamına alınan hastalara ait tüm veriler yazarlar tarafından toplandı. Hastaların ortalama yaş $35,9+9,54$ yıl (25-50 yıl aralığında), 23'ü (\%79,3) kadın, 11'si $(\% 20,7)$ erkekti. 34 hastanın pre-op ağırlık ortalaması $132,93 \pm 19,25$ kg iken, postop 4. yıl $83 \pm 13,90 \mathrm{~kg}$ oldu. Ameliyat esnasında ortalama BMi: $49,8 \pm 7,3 \mathrm{~kg} / \mathrm{m}^{2}$ idi. LSG ameliyatı olmuş 34 hastanın 4 yıl sonunda BMi: 29,18 $\pm 5,6$ $\mathrm{kg} / \mathrm{m}^{2}$ olarak bulundu $(p=0,001)$. Erkek ve kadın hastalar arasında yaş, ağırlık ve BMi değerleri açısından istatistiksel anlamlı fark yoktu (Şekil 1). 


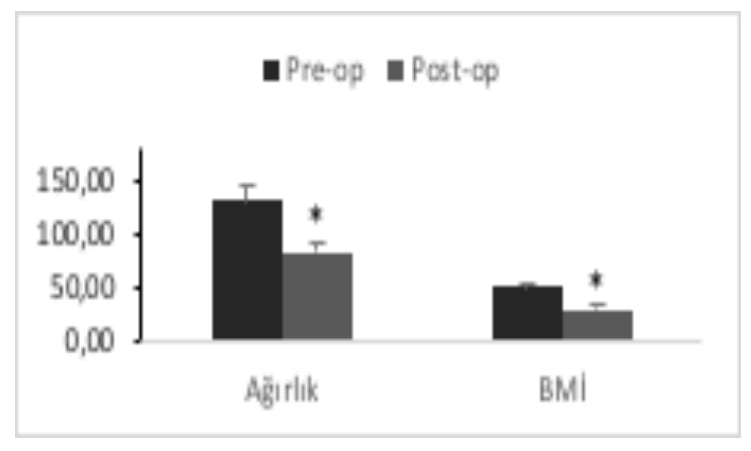

${ }^{*} p=0,001$

Şekil 1. Pre-op ve post-op 4. yıl ağırlık ve BMi değerleri

Çalışma kapsamına alınan 34 hastadan 9'u $(\% 26,4)$ Tip 2 DM olup, 5 hasta insülin, 4 hasta ise OAD tedavisi almaktaydı. LSG sonrası 4. yıl takiplerinde; operasyon öncesi OAD kullanan 4 hastanın tamamı (\%100) OAD'yi, insülin kullanan 5 hastanın 4'ü (\%80) insülini bıraktı. Hastaların pre-op kan glukoz ortalama değeri $111,33 \pm 22,44 \mathrm{mg} / \mathrm{dL}$ idi. 4 . yıl kan glukoz ortalama değeri $94,58 \pm 36,04 \mathrm{mg} / \mathrm{dL}$ bulundu $(p=0,0001)$. Ameliyat öncesi diyabet ilacı kullanmadığı halde, post-op 4. yılda diyabet ilacı kullanımına başlayan hasta yoktu.

34 hastadan 8'u $(\% 23,6)$ pre-op, HT tanısı ile takip edilmekteydi. HT'si bulunan hastaların 4'ü kombine 4'ü tekli medikal tedavi almaktaydı. LSG sonrası 4. yıl takiplerinde; operasyon öncesi antihipertansif ilaç kullanan 8 hastadan 4 'ü $(\% 57,1)$ ilacı bıraktı. Ameliyat öncesi antihipertansif ilaç kullanmadığı halde, post-op 4. yılda antihipertansif ilaç kullanımına başlayan hasta yoktu.

Şekil 2'de gösterildiği gibi, çalışmadaki 34 hastanın pre-op trigliserid düzeyi 157,5 $\pm 78,6$ $\mathrm{mg} / \mathrm{dL}$ iken; post-op 4. yıl trigliserid düzeyi $100,6 \pm 46,3 \mathrm{mg} / \mathrm{dL}$ bulundu $(p=0,002)$. Hastaların pre-op total kolesterol değeri $200,51 \pm 53,31 \mathrm{mg} /$ dL iken, post-op 4. yıl 176,29 $\pm 45,43 \mathrm{mg} / \mathrm{dL}$ olarak ölçüldü $(p=0,002) .34$ hastanın pre-op HDL değeri $42 \pm 8,4 \mathrm{mg} / \mathrm{dL}$ iken, post-op 4 . yıl $53,5 \pm 16,9 \mathrm{mg} / \mathrm{dL}$ olarak ölçüldü $(p=0,002)$.

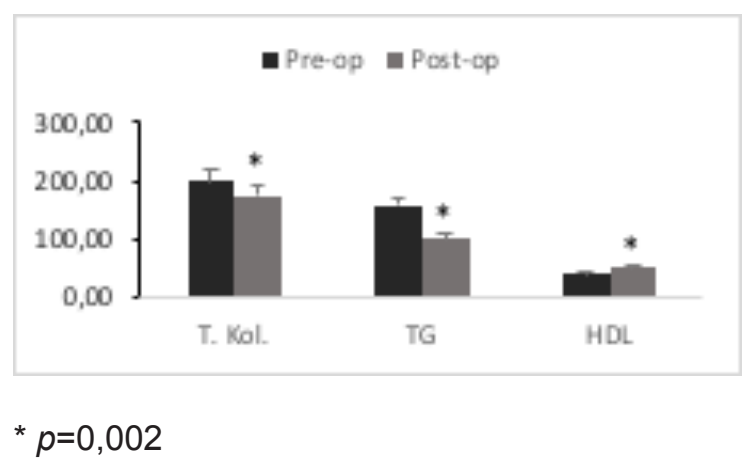

Şekil 2. Pre-op ve post-op 4. yıl T. kolesterol, Trigliserid ve HDL değerleri.

Çalışmaya dahil edilen hastalarda pre-op girelin değeri $672 \pm 143 \mathrm{pg} / \mathrm{ml}$ iken, post-op 4.yıl girelin değeri $164 \pm 43 \mathrm{pg} / \mathrm{ml}$ olarak ölçülerek istatistiksel anlamlı $(p=0,001)$ düşüş gösterdi.

Çalışma grubundaki hiçbir hastada, majör komplikasyon ya da takip süresince mortalite izlenmedi.

\section{Tartışma}

Sleeve gastrektomi, başlangıçta, duodenal switch ile biliopankreatik diversiyonun bir parçası olarak Hess ve Hess tarafından 1999'da tanımlanmıştır [13]. Almogy ve ark. 2004'te, sadece laparoskopik sleeve gastrektomi uygulanan hastalarda faydalı sonuçları bildirdiler [14]. Bu gözlem, dünya çapında laparoskopik sleeve gastrektominin 2003'te neredeyse 0 iken 2008 'de \%4 ila \%7'ye ve 2012 'de \%27'den fazla bir artışına neden oldu [15].

Bariatrik cerrahiden sonra kalıcı kilo kaybı, bariatrik cerrahide önemli bir hedeftir ve genellikle prosedürlerin başarısının ölçüldüğü en önemli sonuç parametresidir. Çalışmamızın 4 senelik uzun dönem takipleri sonucunda, hastalarımıza ait BMi değerlerinin ortalama 49,8'den 29,18'e düştüğünü bulduk. Çıkan bu sonuç daha önce bu konuda yapılmış çalışmalara uygun gözükmektedir $[4,16]$.

Bununla birlikte, bariatrik topluluğun laparoskopik sleeve gastrektominin uzun süreli etkinliği üzerine deneyimi hala yetersizdir. Çoğu yazar ikinci ve üçüncü yıla kadar sürekli kilo kaybı bildirmektedir. Bu süreden sonra, bazı hastalar kilo alıyor gözükmektedir. Bununla beraber, sadece birkaç rapor, 5 yılı aşkın verileri vermektedir [17]. Gadiot ve ark. tarafından 2017 yılında yayınlanan 8 yıla kadar LSG etkileri ve 
sonuçlarını değerlendiren çalışmaya göre, obezite ile ilişkili birtakım komorbidite, LSGıden 5 yıl sonra iyileşmiştir [18].

Çalışma kapsamına aldığımız hastaların metabolik parametrelerindeki düzelmeler çalışmanın amacını destekleyici bir unsur olarak karşımıza çıkmaktadır. Hastalarımızın genelinde yaklaşık \%12'lik bir düşüş göstermiştir. Trigliserid düzeyleri ise yaklaşık \%30 civarı bir düşüş göstermiş ve HDL değerleri de \%25 yükselme göstermiştir. 4 yıllık takip sonucunda elde ettiğimiz veriler, hastaların kilo kaybından kaynaklı gördüğü faydaların yanında metabolik olarak da ciddi yarar gördüğünü düşündürmektedir.

Çalışmamızda, LSG, tüm hastalarda Tip 2 DM'nin düzelmesine neden oldu. 4. yıl sonunda tip 2 DM olan hastaların \%88sinde tam bir remisyon sağlandı. Benzer prospektif çalışmalarda, Lee ve ark. [19] ve Abbatini ve ark. [20] LSG'den sonraki 12. ayda, sırasıyla $\% 50$ ve \%88,8 >lik remisyon oranları bildirmiştir. Aynı şekilde HT tanısı ile takipli hastalarımızda 4 yıllık takip sonuçlarına göre, \%57,6 oranında bir remisyon sağlandı. Sarkhosh ve ark. 2012 yılında yayınladığı, LSG ameliyatı yapıımış olan 33 çalışma ve 3997 hasta içeren derlemesinde çalışmamıza oldukça benzer şekilde HT'si olan hastalarda remisyon oranı \%58 bulunmuştur [21].

Bunun yanında, değişik tipteki bariatrik cerrahilerin girelin düzeylerine etkisi, çelişkili sonuçlar veren çok sayıdaki çalışmada analiz edilmiştir [22-24]. Ayrıca, LSG uygulanan olgularda yapılan bir çalışmada, girelin düzeyleri 12 ay sonra belirgin bir şekilde azalmış ve daha sonra birkaç yıl daha kalıcı olmuştur [25]. Çalışmamızda elde ettiğimiz post-op 4. yıl sonundaki girelin düzeyindeki düşüş Bohdjalian ve ark. elde ettiği sonuca uymaktadır. Bu düşüşün muhtemel nedeni girelin üretiminin baskın bölgesi olan gastrik fundusun LSG ile rezeksiyonudur. Girelin düzeyindeki bu düşüş glikoz homeostazının iyileştirilmesinde rol oynuyor gözükmektedir.

Diğer yazarların görüşleri ve kendi gözlemlerimize göre, metabolik parametrelerin iyileştirilmesinin, LSG prosedürünün bir sonucu değil, kilo kaybının sonucu olduğu kanısına varıyoruz. LSG sonrası girelin düzeyi, midenin fundus ve gövdesinin rezeksiyonu nedeniyle azaltılarak karbonhidrat ve yağ tüketimini düşürür. LSG ile obezite tedavisi Tip 2 DM ve HT gibi komorbiditelerin semptomlarını azaltarak hastaların sağlık durumları üzerinde doğrudan yararlı etkiye sahiptir.

Elde ettiğimiz verilere göre, LSG morbid obezitenin tedavisinde emniyetli ve etkin bir yöntemdir, uzun dönemli olumlu metabolik etkilere sahiptir, yaşam kalitesi ve konforunu artırıcı bir prosedürdür, morbidite ve mortalitesinin çok düşük olması ile de güvenle uygulanabilir.

Çıkar ilişkisi: Yazarlar çıkar ilişkisi olmadığını beyan eder.

\section{Kaynaklar}

1. Ogden CL, Carroll M, Fryar CD, Flegal KM. Prevalence of obesity among adults and youth: United States, 2011-2014: US Department of Health and Human Services, Centers for Disease Control and Prevention (CDC), National Center for Health Statistics; 2015;1-8.

2. Nakatani T, Kim HJ, Kaburagi Y, Yasuda K, Ezaki O. A low fish oil inhibits SREBP-1 proteolytic cascade, while a high-fish-oil feeding decreases SREBP-1 mRNA in mice liver: relationship to anti-obesity. J Lipid Res 2003;44:369-379. https://doi.org/10.1194/jlr.M200289JLR200

3. Guh DP, Zhang W, Bansback N, Amarsi Z, Birmingham $\mathrm{CL}$, Anis $\mathrm{AH}$. The incidence of co-morbidities related to obesity and overweight: a systematic review and meta-analysis. BMC Public Health 2009;9:88. https:// doi.org/10.1186/1471-2458-9-88

4. Arias E, Martínez PR, Ka Ming Li V, Szomstein $\mathrm{S}$, Rosenthal RJ. Mid-term follow-up after sleeve gastrectomy as a final approach for morbid obesity. Obes Surg 2009;19:544-548. https://doi.org/10.1007/ s11695-009-9818-6

5. Menenakos E, Stamou KM, Albanopoulos K, Papailiou J, Theodorou D, Leandros E. Laparoscopic sleeve gastrectomy performed with intent to treat morbid obesity: a prospective single-center study of 261 patients with a median follow-up of 1 year. Obes Surg 2010;20:276-282. https://doi.org/10.1007/s11695-0099918-3

6. Gumbs AA, Gagner M, Dakin G, Pomp A. Sleeve gastrectomy for morbid obesity. Obes Surg 2007;17:962-969.

7. Müller TD, Nogueiras R, Andermann ML, et al. Ghrelin. Mol Metab 2015;4:437-460. https://doi.org/10.1016/j. molmet.2015.03.005

8. Sato $T$, Ida $T$, Nakamura $Y$, Shiimura $Y$, Kangawa $K$, Kojima M. Physiological roles of ghrelin on obesity. Obes Res Clin Pract 2014;8:405-413. https://doi. org/10.1016/j.orcp.2013.10.002 
9. Eriksson J, Lindström J, Tuomilehto J. Potential for the prevention of type 2 diabetes. British Medical Bulletin. 2001;60:183-99.

10. Knowler WC, Barrett-Connor E, Fowler SE, et al. Reduction in the incidence of type 2 diabetes with lifestyle intervention or metformin. $\mathrm{N}$ Engl J Med 2002;346:393-403. https://doi.org/10.1056/ NEJMoa012512

11. Rizzello M, Abbatini F, Casella G, et al. Early postoperative insulin-resistance changes after sleeve gastrectomy. Obes Surg 2010;20:50-55. https://doi. org/10.1007/s11695-009-0017-2

12. Basso N, Capoccia D, Rizzello M, et al. First-phase insulin secretion, insulin sensitivity, ghrelin, GLP-1, and PYY changes $72 \mathrm{~h}$ after sleeve gastrectomy in obese diabetic patients: the gastric hypothesis. Surg Endosc 2011;25:3540-3550. https://doi.org/10.1007/s00464011-1755-5

13. Hess DS, Hess DW. Biliopancreatic diversion with a duodenal switch. Obes Surg 1998;8:267-282. https:// doi.org/10.1381/096089298765554476

14. Almogy G, Crookes PF, Anthone GJ. Longitudinal gastrectomy as a treatment for the high-risk superobese patient. Obes Surg 2004;14:492-497 https://doi. org/10.1381/096089204323013479

15. Buchwald H, Oien DM. Metabolic/bariatric surgery worldwide 2011. Obes Surg 2013;23:427-436. https:// doi.org/10.1007/s11695-012-0864-0

16. Himpens J, Dobbeleir J, Peeters G. Long-term results of laparoscopic sleeve gastrectomy for obesity. Ann Surg 2010;252:319-324. https://doi.org/10.1097/ SLA.0b013e3181e90b31

17. Hodge A, Dowse G, Gareeboo H, Tuomilehto J, Alberti $\mathrm{K}$, Zimmet $\mathrm{P}$. Incidence, increasing prevalence, and predictors of change in obesity and fat distribution over 5 years in the rapidly developing population of Mauritius. Int J Obes Relat Metab Disord 1996;20:137146.

18. Gadiot RP, Biter LU, van Mil S, Zengerink HF, Apers J, Mannaerts GH. Long-term results of laparoscopic sleeve gastrectomy for morbid obesity: 5 to 8 -year results. Obes Surg 2017;27:59-63. https://doi. org/10.1007/s11695-016-2235-8

19. Lee WJ, Ser KH, Chong K, et al. Laparoscopic sleeve gastrectomy for diabetes treatment in nonmorbidly obese patients: efficacy and change of insulin secretion. Surgery 2010;147:664-669. https://doi.org/10.1016/j. surg.2009.10.059

20. Abbatini F, Capoccia D, Casella G, Coccia F, Leonetti F, Basso N. Type 2 diabetes in obese patients with body mass index of $30-35 \mathrm{~kg} / \mathrm{m}$ 2: sleeve gastrectomy versus medical treatment. Surg Obes Relat Dis 2012;8:20-24. https://doi.org/10.1016/j.soard.2011.06.015
21. Sarkhosh K, Birch DW, Shi X, Gill RS, Karmali S. The impact of sleeve gastrectomy on hypertension: a systematic review. Obes Surg 2012;22:832-837. https://doi.org/10.1007/s11695-012-0615-2

22. Beckman LM, Beckman TR, Earthman CP. Changes in gastrointestinal hormones and leptin after Rouxen-Y gastric bypass procedure: a review. J Am Diet Assoc 2010;110:571-584. https://doi.org/10.1016/j. jada.2009.12.023

23. Kotidis EV, Koliakos G, Papavramidis TS, Papavramidis ST. The effect of biliopancreatic diversion with pyloruspreserving sleeve gastrectomy and duodenal switch on fasting serum ghrelin, leptin and adiponectin levels: is there a hormonal contribution to the weight-reducing effect of this procedure? Obes Surg 2006;16:554559. https://doi.org/10.1381/096089206776944940

24. Karamanakos SN, Vagenas $\mathrm{K}$, Kalfarentzos $\mathrm{F}$, Alexandrides TK. Weight loss, appetite suppression, and changes in fasting and postprandial ghrelin and peptide-YY levels after Roux-en- $Y$ gastric bypass and sleeve gastrectomy: a prospective, double blind study. Ann Surg 2008;247:401-407. https://doi.org/10.1097/ SLA.0b013e318156f012

25. Bohdjalian A, Langer FB, Shakeri-Leidenmühler $S$, et al. Sleeve gastrectomy as sole and definitive bariatric procedure: 5 year results for weight loss and ghrelin. Obes Surg 2010;20:535-540. https://doi.org/10.1007/ s11695-009-0066-6

Etik onayı: $\mathrm{Bu}$ çalışma, Pamukkale Üniversitesi Tıp Fakültesi Genel Cerrahi Anabilim Dalı tarafından yürütüldü ve çalışma için Pamukkale Üniversitesi Girişimsel Olmayan Etik Kurulu'ndan 22.11.2014 tarih ve 2014/15 sayı ile onay alındı.

$\mathrm{Bu}$ çalışma, Pamukkale Üniversitesi Bilimsel Araştırma Projeleri (BAP) tarafından desteklenmiştir. 9. Cerrahi Araştırma Kongresi'nde sunuldu. 